\title{
THE EARLY PHILOSOPHICAL ESSAYS
}

The following review essay, reprinted with minor adjustments from The Russian Review, vol. 54, number 1 (January 1995), celebrates that moment in the Bakhtin Industry when the impact of his earlier, philosophically abstract work became available in English. Research on these early texts, believed by Bakhtin to be lost and published for the most part posthumously, made possible a responsible investigation of Bakhtin's intellectual origins in the largely German traditions of Romantic philosophy, Kantianism, and phenomenology.

REVIEW ESSAY

\section{BAKHTIN AT 100: LOOKING BACK AT THE VERY EARLY YEARS} (1995)

Bakhtin, M. M. Toward a Philosophy of the Act. Translation and Notes by Vadim Liapunov. Edited by Vadim Liapunov and Michael Holquist (Austin: University of Texas Press, 1993).

"...Aesthetic activity as well is powerless to take possession of that moment of Being which is constituted by the transitiveness and open event-ness of Being." Thus begins this little book under review, Bakhtin's maiden essay (ca. 1919-22), and a less grateful opening sentence by a famous literary critic can scarcely be imagined. Vadim Liapunov has accomplished the same minor miracle with this early, unfinished and unreworked seventy-page fragment - which appears to be part of the introduction to a far vaster project of Bakhtin's, never finished and first published in Russian in 1986 as K filosofii postupka - that he accomplished in 1990 with its lengthier sequel, "Author and Hero in Aesthetic Activity." With this publication, almost all of

1 Michael Holquist and Vadim Liapunov, eds., Art and Answerability: Early Philosophical Essays by M. M. Bakhtin, trans. and notes by Vadim Liapunov, supplement translated 
Bakhtin's extant writings have been moved into English. ${ }^{2}$ What sort of a work is this, and why should people who value Bakhtin's later, more accessible ideas of polyphony, dialogism and carnival make the effort to read it?

We should make the effort, I believe, for two reasons. First, Bakhtin was published in Russian and translated into Western languages "inside out," with the middle-period writings rising meteorically to fame while the earliest and latest texts were still unavailable, in some cases their existence unsuspected. A major thinker deserves to be known in his genesis. Second, the complex concept of an answerable architectonic self - as opposed to the more straightforward, familiar dialogic and carnivalistic selves of the later writings - is first developed by Bakhtin in these early manuscripts; he returned with increasing frequency to the model in his mature years. In his notes from 1970-71, Bakhtin called this study of comparative selfhoods "philosophical anthropology." He incessantly reformulated its major concerns: "the nature of one's image of oneself," the degree of "self-sensation and self-awareness" in this image, and the role the other must play to keep this image from collapsing into the sterile duplications of a "person at the mirror," a tempting but fraudulent condition permitting a single consciousness to finalize its own image. For half a century, Bakhtin recruited major primary creators - Dostoevsky, Goethe, Rabelais - to help him interrogate this cluster of problems.

Bakhtin's early period is an enigma. For several years now, the journal Chelovek has been running partial transcripts of interviews conducted by a Soviet Mayakovsky scholar in 1973-74 with the aged Bakhtin. ${ }^{3}$ Recounting

by Kenneth Brostrom (Austin: University of Texas Press, 1990). [Henceforth Art and Answerability.] The dating of these early manuscripts is disputed; Brian Poole has argued that internal evidence suggests they might have been written as late as 1926, when Bakhtin first acquainted himself with the work of Max Scheler.

2 The Russian edition of the Collected Works of Bakhtin, currently being compiled in St. Petersburg under the general editorship of Sergei Bocharov, will contain some texts not yet published in the West. Of these the most important are several hundred additional pages of the manuscript on the Bildungsroman and on Goethe (researched by the Canadian scholar in Marburg, Brian Poole), and comments on Shakespearean drama, Dante, Heine and Goethe from Bakhtin's dissertation on Rabelaisian carnival that were not included in the 1975 book on Rabelais (this material was first published in Voprosy filosofii, 1992, no. 1).

3 The interviews were conducted over seventeen hours in 1973-74 by the Mayakovskii scholar V. D. Duvakin. Three installments, which take Bakhtin's life up to the mid-1920s, appeared as "Razgovory s Bakhtinym," in Chelovek, 1993, no. 4:136-53, no. 5:131-43, and no. 4-6:158-73. In 1996, the interviews were published in paperback as Besedy V. D. Duvakina s M. M. Bakhtinym (Moscow: Izdatel'stvaia gruppa Progress, 1996), and then retitled (to highlight the most famous party) and reissued in 2002 as M. M. Bakhtin: Besedy s V. D. Duvakinym (Moscow: Soglasie, 2002). 
his youth, Bakhtin claims he had always wanted to be a moral philosopher, a "myslitel" [thinker]; literary scholarship was for him a safe refuge from politics during those years when others were being harassed, organized, recruited. He insists that as a young college student in Petrograd he had been "absolutely apolitical." He lamented not only the October Revolution but the prior February abdication as well, predicting that it would end badly and "extremely;" he went to no political meetings, profoundly distrusted the Provisional Government under Kerensky, and continued to sit in libraries and read books. The image of a learned, apolitical, urbane, witty, fastidious and aristocratic young Bakhtin that emerges from these memoirs is in some tension, of course, with the mass-oriented Bakhtin popular in Western radical circles. But it meshes well with the philosophical core being vigorously restored to Bakhtin's thought in Russia today, in conference volumes, special Bakhtin journals, and notably the 1992 volume by the Russian Academy of Sciences, M. M. Bakhtin kak filosof - the latter containing essays on Bakhtin's Christianity, on his refutation of ethical relativism, and detailed notes by Lev Pumpiansky on Bakhtin's lectures from the mid-1920s on religious philosophy, Bergson, and Kant's Critique of Pure Reason. Deeply influenced by the neoKantian Marburg School and perhaps by the fin-de-siècle spirit of Nietzsche and Vladimir Soloviev, Bakhtin began his own life of the mind by posing very large questions, among them the "contemporary crisis of philosophy."

As Michael Holquist points out in his excellent, overly brief introduction to this volume, Bakhtin turned not so much to the neo-Kantians as to Kant himself. That great corpus of writings both attracted and repelled. What appealed about Kant, and what would become recurring motifs in Bakhtin's own thought, was Kant's unbending insistence on moral criteria for human behavior, his inclusion of time and space as participants in-not mere parameters for - our human understanding, and his head-on confrontation with the crucial question: How much can our reason know apart from lived experience? What alienated Bakhtin was the readiness with which Kant sought to avoid ethical relativism by positing the general or universal case. Relativism, Bakhtin was convinced, could be avoided at less cost. And hence he cast his inquiry as a philosophy not of a transcendent categorical "as if" or moral imperative, but of "the concrete step taken," postupok, the individual act.

In brief, and bringing down to far cruder earth the abstract Germanic lexicon employed by the young and erudite Bakhtin, the argument of the essay is this. A crisis in philosophy occurs when the realm of "culture" - that is, accumulated events, congealed content, human accomplishment that can exist autonomously, without immediate authors attached to it - is severed 
from the realm of "life" (actions personally committed by us). Whereas life feels shapeless and open, cultural content lends itself to arrangement in terms of norms and inner necessity. It feels good - indeed, fatally good - to lose ourselves in these structures (as Bakhtin puts it, we feel most sure of ourselves, most lucid and at home, where we are not actually present); but we should be cautious, he warns, because precisely in such abstract realms are we the most "determined, predetermined, bygone, finished" (9). In fact there are no moral, or creative, or psychical norms. There is no general theoretical "ought" at all, but only the obligation of the individual moral subject. Genuine subjects must do more than merely discipline themselves to obey a fixed standard, for nothing is easier for a strong will than to posit its own law and then follow it - or, alternatively, to assign success and/or failure to already completed acts in their "theoretical transcription" (26-27). An ethical subject must engage in the riskier, more humbling, present-tense practice of "participative" thinking [uchastnoe myshlenie]. This entails active empathizing: an entering-in to the other's position followed not by an identification with that other (in Bakhtin's world, any duplication or fusion is always sterile) but by a return to one's own position, the only place from which I can understand my own unique "ought" in its relationship to another.

To acknowledge this need for interpenetration and constant oscillation between self and other is not, however, to embrace Henri Bergson's solution, then much in vogue, which holds that we are largely "vital force" and unfixable "flow" (Bakhtin sees both these qualities as hopelessly theoretical). Nor is it to endorse relativism; quite the contrary. It is to insist on something infinitely more difficult than either: uninterrupted choice-making in the moral sphere and a willingness to answer for all one's acts in time, as one does them, which will result in a dynamic, "architectonically" whole personality. The self here is uniquely situated, non-generalizable, risk-taking and judging. Like all Bakhtin's constructs, it is post-Einsteinian: its consciousness is situated in a world that knows relativity. But this world also knows truth. And to invoke a defense often mounted on behalf of the American pragmatists, there is a massive difference between relativism and relativity. Relativism can work to invalidate moral judgment. In a universe governed by relativity (or better, relationalism), however, precisely because there are no single fixed points, moral judgment - and one's subsequent personal responsibility for moral judgments over time - is all the more indispensable. It is from this position that Bakhtin elaborates his own revision of Kant.

We might simplify Bakhtin's Kantian quest in this way: To escape being a mere random occurrence in life, to what sort of continuity do I aspire? 
"A philosophy of life can only be a moral philosophy," Bakhtin writes; "a life that has fallen away from answerability cannot have a philosophy; it is, in its very principle, fortuitous and incapable of being rooted" (56). As a principle, this is easy and gratifying to endorse. But to what precisely are we answerable? Must there exist a normative ethical model against which I measure my act - or might there be other continuities and types of rootedness? To these questions Bakhtin insists that we answer not to any theoretical imperative or law, but only to our own unique "act-taking I." But how does an "I" cohere?

This problem fascinated the young Bakhtin. The coherence of culture, he intimates, takes care of itself (here Americans can only wonder at the awesome, identity-bestowing hold of Russian culture on its own communicants); one recognizes culture as such by its qualities of interrelatedness and cohesiveness. What, then, makes a human whole possible, since persons must participate in so many fragmented things and are subject to so many pressures beyond their control? Here Bakhtin resists the easy intuitivist explanation so popular with his generation and devises in its place a cautiously interactive model that we can now recognize as a rudimentary, preverbal form of dialogue.

The basic components of this model, in Bakhtin's German-inflected Russian categories, are dan and zadan, "what is given" and "what is posited." Life presents us with "givens" [dannost']: formless disasters, undeserved illnesses, mindless revolution, unexpected good luck. In lived experience, as a rule, we do not come upon already existent unities or wholes. What makes us whole - Bakhtin might even say, the only thing that can make us whole - is a response. It is rarely within our power to initiate and guarantee wholes in the world at large (at least in no world that Bakhtin ever knew), but it is always within our power to initiate a whole in ourselves through our own responsive act.

This apparently straightforward solution to identity is difficult to grasp, however, because our patterns of thought have been shaped by a false duality between transient and permanent, or between what Bakhtin calls the "once-occurrent" and the true. A performed act always has a sort of unity to it; that is, integrated reasons for its occurrence can be found. But it only happens once. Unhappily, Bakhtin notes, we have grown accustomed to associating the truth of an event with what is repeatable, constant, and universal in it, whereas in fact the opposite obtains: only the once-occurrent is fully true. "In this sense," Bakhtin writes, "the very word unity [edinstvo] should be discarded as overly theoretized;" key to understanding is "not unity but uniqueness" [edinstvennost'] (37). Abstract logic will not help us grasp this uniqueness or once-occurrent unity. But we do have a marvelously 
flexible tool at our disposal for this purpose, which is language. As Bakhtin notes in this early intimation of dialogism, words - with all their inevitable "fullness" - are ideally suited for "participative" modes of being. It is through words that the material of the world is most easily transformed from a state of givenness to a state of "positedness," zadannost', awaiting a task. Bakhtin intimates further that only projections and tasks, that is, only what is posited for future solution rather than given in the past - can be talked about. Mere givenness, ready-made and always already there, is too coincident with itself and thus too indifferent, too inert, to require from us a conversation. In fact it cannot really be cognized at all, for cognition itself, Bakhtin insists, is a questing relationship among diverse consciousnesses.

The implications of this position (not, of course, wholly original with Bakhtin) are immense. In the second half of Toward a Philosophy of the Act, Bakhtin elaborates loosely on them - and while reading this difficult little book it might help to keep steadily in mind the main target of his concern. It is always the split between culture and life, and how to bridge that gap so that both sides are obligated. Merely to bring form and content together is insufficient. What is needed to achieve the proper clamp between culture and life is an attitudinal orientation that Bakhtin calls intonation or tone. "Emotional-volitional tone" is no passive vehicle; it is not something added to an utterance after the content has already been shaped. Nor is it mere reflex, a "passive psychic reaction." It is an external manifestation of the energy connecting that which is given (the world I wake up to; "culture in general" from which I receive my forms) with that which is not yet given, that which is "yet to be determined" or formed (that is, my life). My choice of "intonation" works on me in such a way that I cannot, however much I might desire it, lose myself in an act; on the contrary, I am forced to find myself in it. Tone permeates my act as soon as I "experience an experience as mine" (36).

"In all of Being I experience only myself - my unique self — as an I," Bakhtin writes (41). The motif of "mine," "my uniqueness," my own "uniquely obligated self" (also referred to as "once-occurrent Being as event" or my "nonalibi in Being" [40]) is a leitmotif throughout the essay. Such an egocentric focus might seem odd to readers familiar with the more famous, dialogic, other-directed Bakhtinian categories, where a self-confident first person singular, if it survives at all, is something of an embarrassment. For is not the "I" made up of many voices and various perspectives, is it not always conditioned by the needs of an Other, is not the whole idea of "mine" too reductive, solipsistic, static, monologic? Not at all — and why it is not is of crucial importance in grasping the dialogism to come. 
Bakhtin, it could be said, began his philosophical career worrying about too little "I" in the world, not too much. He held that until an "I" could generate and answer for its own whole truth - that is, until it is willing to "undersign" or "put its signature on" an act - it is in no condition to interact with others. Perhaps surprisingly, Bakhtin insists that the unity (or, as he would prefer to put it, the uniqueness) that makes up my identity has little to do with the content of the acts I sign (truths or lies, goods or evils, inner consistency or flagrant contradiction), and everything to do with my acknowledging them as mine. My personality, he writes, is a "unity of answerability, not a constancy in content" (39). Several startling and - dare I say it? - refreshing things flow from this assumption.

First, Bakhtin is more or less indifferent to questions of justice, victimization, and such political-ethical questions as "Who is to blame?", "Do we get what we deserve?", "Why did this happen to me?", or "How can I express my rights, recover my rights, or enforce my rights in my struggle against an uncomprehending world?" The supremely apolitical Bakhtin, a philosophical stoic, is uninterested in self-pity and suspicious of those legalistic sorts of empowerment. He is concerned solely with one crucial aspect of an act: once it has happened to me, am I willing to sign it? My signature on an act, note, does not mean that I caused it or that I approve of it; it means only that I acknowledge it as an existing fact and that I will not withdraw into fantasy, denial, or utopia in the face of it. I agree to participate in it. Recall the eternal Russian question "Chto delat'?" [What Is To Be Done?], which has been answered over the years with such stiffneckery and whimsicality by Nikolai Chernyshevskii, Vasily Rozanov and Vladimir Lenin. To this question Bakhtin would say: Until a given, unique, unrepeatable "I" signs an act, nothing can be done - not for justice, nor for victims, nor for the whole huge world of the "non-I." Consciousness can move forward only in this answerable manner, because "I exist in a world of inescapable actuality, not of contingent possibility" (44). Here is Bakhtin before he arrived at the word-with-a-loophole and before the indestructible jesters of carnival began relativizing all values and laughing at death.

Second, Bakhtin insists on a pragmatic, concrete, nontransferable, hands-on criterion for obligation. This too is in subtle counterpoint with traditional Russian cultural values of collectivism, maximalism, communal sacrifice and poetic transcendence. "It is not the content of an obligation that obligates me, but my signature below it," Bakhtin writes (38); in fact, the more fastidiously we unify content in terms of a theory, "the poorer and more universal is the actual uniqueness" of that content (39). Thus my 
integrity and continuity are guaranteed not by stringing together a series of consciously chosen, compatible units of content - that human beings should be so fortunate to have that choice in their everyday lives - but by a string of personal signatures. Whatever I sign, I must work with; if I make a habit of refusing to sign, for whatever reason, I forfeit identity.

Categorical imperatives follow, but they are not Kant's. Since I am irreplaceable, I have irreplaceable potential and am obliged to act to "actualize my uniqueness" (41). Not to do so is to abdicate, to wish to be in another's place, or (worst of all) to attempt to live from an abstract, nonexistent time and place - in Bakhtin's parlance, to become a pretender. No question about it, irreplaceability and uniqueness guarantee anguish and doubt. There is something piercingly lonely about the entire model. But as compensation I can be assured that no initiative I take toward actualization can ever be entirely arbitrary; my act is always "unindifferent." Here Bakhtin stresses one easily misunderstood point. To live "from within myself and from my own unique place" does not mean to live for myself, that is, it is not, in the crude sense of the word, "selfish" $(48-49,60)$. Thinkers (and in this context, somewhat unjustly, Bakhtin mentions Nietzsche) who misconstrue this distinction might strive to free the self from the constraints of uniqueness. Since, however, meaningful freedom never happens all at once but is brought on incrementally, through repeated signatures and commitments, such liberators are left with "the absurdity of contemporary Dionysianism" (49).

Wonderful local insights abound in Bakhtin's essay, but three are especially telling: how his model deals with envy, politics, and love. Envy first. Since every unity is a uniqueness, and since our time-and-place at any moment is nontransferable, envy of another person is an ontological impossibility. After all, no one but I can do my specific "signed" task, and no one but the other can do the other's task. An envious orientation is simply an ignorant one. (This thought won't help us get through a bad day, but on a good day it can inspire us and save a great deal of time.) Or take his comments on politics, so unnervingly Russian. Similar to many of the Slavophiles, to Leo Tolstoy, and more recently to Alexander Solzhenitsyn, Bakhtin is suspicious of organized political activity and unimpressed by the benefits it might bring. Politics is always and on principle hostile to ethics. Persuasive moral scenarios contain two or three persons; as soon as you can no longer see or talk eye-to-eye with someone, as soon as you start thinking like a class-action suit, your effectiveness in the cosmos becomes less, not more. According to Bakhtin, "political answerability" and representational procedures, even the most benign, are fraught with distancing, depersonalization, ritualization — and 
can lead to unmanageable pride ("One has to develop humility to the point of participating in person and being answerable in person" [52]).

Safer and more satisfying than politics is Bakhtin's theory of love. It is, among other things, a lovely revisionist reading of the routine Christian adage that we should "love our neighbor as ourselves." This is difficult to do, Bakhtin intimates, not because we are innately selfish but because technically I cannot love my own self; I lack the categories for it. (The best I can do is fantasize some hypothetical other who might smile back at me and love me: this is the awful temptation of the mirror.) Our cognitive and creative forces are fueled not by reflections but by answerability, that is, by interaction between different, only temporarily consummated selves. During this interaction we do confer form on one another - in fact, such consummation is a gift we continually bestow upon other selves because each of us craves and deserves definition - but as long as the other is alive, we can never finalize his content or personality once and for all. Thus loving my neighbor as myself is not only poor advice (as if self-love were ever a model for anything); such activity is, strictly speaking, impossible. We should love our neighbor as our neighbor, as something distinct from us and only imperfectly translatable into our own terms.

The implication here is that before anything can be loved, boundaries must be confirmed and respected - for I can "answer" only across a boundary. For Bakhtin, the more of these boundaries and differentiations, the better. In his understanding, our psyches are constructed to be curious about difference, not hostile to it or frightened by it. What marks a "true love experience," then, is nothing necessarily erotic or possessive - and certainly nothing neurotic or compulsive - but rather a cognitive quality, a concentration of attention that enriches the beloved over time with extraordinarily individuated responses. "Lovelessness, indifference, will never be able to generate sufficient power to slow down and linger intently over an object, to hold and sculpt every detail and particular in it" (64). For this reason, Bakhtin concludes, only love can "see" the world with sufficient subtlety to be aesthetically productive. Appropriately, Toward a Philosophy of the Act breaks off on a lengthy "architectonic" analysis of self-other constructs in Pushkin's 1830 love lyric, "Razluka" [Parting].

Why, then, should we read this dense and difficult little book? The availability of Bakhtin's early ethical writings in English makes possible a rapprochement between Western images of Bakhtin (still quite beholden to, even bedazzled by, carnival and by refractive, open-ended dialogue) and the freshly de-ideologized, de-maximalized apolitical Bakhtin currently in 
the ascendancy in post-Communist Russia. Intellectuals over there, painfully sensitized to the dangers of politicized culture and ethical relativism, have paid much more attention than have we to Bakhtin's early philosophical texts. Not surprisingly, many post-Communist thinkers find in the idea of "architectonics" a very productive model. In contrast to the benign, generous, permeable, reversible give-and-take model of the dialogic self, and also in contrast to the transitory, wordless, ever-leaking one-dimensional carnivalistic self (really more a collective body than a self proper), the complexly responsible, ego-oriented and integrated architectonic self is exactly what is needed in our postmodernist, post-Communist times. Of all Bakhtin's "selves," it is this earliest self that is most concerned about individuation and answering for itself among others. While not yet fully dialogic itself, it is in training for the challenges and pitfalls of dialogue. Initiation into dialogue, it would seem, requires disciplined preparatory work. Not fidelity to a set of inherited rules, nor mere instincts and intuitions of love, nor vague intimations of a faceless wholeness will suffice.

To translate and package this complex philosophical fragment demands a high quality of professionalism. Vadim Liapunov (whose reputation as a leading scholar of the early texts is high in Russian Bakhtin circles) does an exemplary job with the scholarly apparatus of Toward a Philosophy of the Act. He provides not just the necessary references - thirty pages of notes - but also the etymology, largely German, of Bakhtin's most important terms: their genesis, ambivalences, and where the curious Anglophone lay philosopher might repair for more information. In the process, Liapunov reconstructs the history of Bakhtin's intellectual debts and reading habits, a task that Bakhtin himself - always supremely the servant of ideas and not of his own curriculum vitae - never bothered publicly to do. He simply read things, thought them through from his special perspective, and wrote down his reactions. For as Bakhtin remarked magisterially in his 1924 essay assessing formalist approaches to literature (the only substantial early piece actually prepared by its author for publication): "We have freed our study from the superfluous ballast of citations and references, for they lack any direct methodological significance in studies of a nonhistorical nature, while in a compressed work of a systematic nature they are entirely superfluous. For the qualified reader, they are unnecessary; for the unqualified, useless."4

4 "The Problem of Content, Material, and Form in Verbal Art," trans. Kenneth Brostrom, in Art and Answerability, 257. 
The point is well taken. But times have changed, we are almost all unqualified, and in any event the major sources for Bakhtin's scholarly activity, given his international fame and high visibility, have become a matter of importance in their own right. Such bibliographical research is all the more imperative because biographical documents for the early period are relatively few. It is likely that Bakhtin never graduated formally from Petrograd University. He was something of a loner, a nonjoiner. If we are to believe his reminiscences fifty years after the fact, his most passionate learning experiences took place not in classrooms but in irregular study circles, one of which, "Omphalos," he recalled as a mix of the satiric spirit of Swift and the tomfoolery and irrepressible creativity of the youthful Pushkin's Arzamas. But Bakhtin censured even "the culture of circles" - which, he remarked, was too often dominated by "typical Russian chatter, chatter, with no serious scholarly papers at all." 5 Bakhtin wrote few letters. There were no children; apart from his wife, the adult Bakhtin had no intimate family. He left no extended memoirs. He remained cordial but formal with his colleagues, correct with his students, and he would never have turned his own personal life, so marked by the insecurity and casual tragedies of his era, into a reference point for any special understanding. His career pattern was decidedly peculiar. He lived by ideas.

In his editions of the early manuscripts, then, Vadim Liapunov has done Bakhtin the great service of taking him absolutely on his own terms. They provide nothing less than a proto-biography of Bakhtin's ideas. As such, Liapunov's work is a labor of love, the sort of love that "slows down and lingers intently" on its subject - and I believe that Bakhtin, for all his cavalier attitude toward the survival of his own written word, would have been astonished and grateful for it. Toward a Philosophy of the Act was transcribed fifty years after the writing, from water-damaged school notepads, barely legible and on the verge of disintegration, extracted from a lumber room in Saransk. The Russian publication of the text, and then this superb English edition, are yet another act that stands to bring Bakhtin the sort of "answerable" immortality that he believed only the word could bring.

5 "Razgovory s Bakhtinym," Chelovek, no. 5 (1993): 132-34, 141. The "circle" under censure was Vol'fil, the "Free Philosophical Association," whose sessions Bakhtin occasionally attended but at which he declined to deliver papers, dissatisfied with its "rhetorical eloquence, mostly of the liberal sort but also of a mystical, idealistic character." 